\title{
PSYCHE
}

\section{THE WORKERS OF VESPA CAROLINA DR. RESEMBLE IN COLORATION THE MALES. A CORRECTION.}

\author{
BY C. H. TURNER, AUGUSTA, GEORGIA.
}

H. W. Lewis in his paper ${ }^{1}$ on the "Vespinae of the United States and Canada," says that the worker of Vespa carolina is similar to the female though smaller. This is an error which it is the purpose of this article to correct. The color pattern of the worker is similar, not to that of the perfect female, but to that of the male.

The above statement is based upon a careful study of the contents of a large nest of Vespa carolina Dr. which I dug out of a red clay bank in Atlanta, Ga., October 10, 1904. The nest was six stories high and contained several hundred workers, several hundred males and several dozen perfect females, besides numerous young in all stages of development.

The color pattern of the perfect female tallies well with that published by Lewis (l. c., p. 180), hence it is evident that Lewis and I are discussing the same species. Since I captured my specimens in the nest, it is evident that the males and workers in my possession belong to the same species as the perfect females. A study of this nest would enable even a casual observer to note that the worker resembles in color pattern, not the perfect female but the male. Indeed, the workers and perfect females are so unlike that one capturing the two in the field, and having no clue to their identity save Lewis' paper, would assign them to two distinct species. It is in the color pattern of the abdomen that the contrast is noticed; although even on the head the pattern is not the same on that of the worker and perfect female.

A description of the perfect female is omitted from this article because such a description would be merely a repetition of Lewis' work. The black and white figure of the perfect female [fig. 5] which accompanies this paper will serve to show how unlike the worker [fig. 1] it is. The usual length of the females in this nest was $21 \mathrm{~mm}$., but some specimens were only $19 \mathrm{~mm}$. long. The head varied in length from $2 \mathrm{~mm}$. to $3 \mathrm{~mm}$., in width from $5.5 \mathrm{~mm}$. to $6 . \mathrm{mm}$., in height from $5.5 \mathrm{~mm}$. to $6 \mathrm{~mm}$. The thorax varied in length from $6 \mathrm{~mm}$., to $7 \mathrm{~mm}$., in width from $6 \mathrm{~mm}$. to $6.5 \mathrm{~mm}$., in height from $6 \mathrm{~mm}$. to $6.5 \mathrm{~mm}$. The abdomen varied in length from 11 $\mathrm{mm}$. to $13.5 \mathrm{~mm}$., in width from $6 \mathrm{~mm}$. to $8 \mathrm{~mm}$., in height from $5.75 \mathrm{~mm}$. to $6 \mathrm{~mm}$.

1 Trans. Amer. Ent. Soc., vol. XXIV, June, 1897, p. 180. 
Description of the Worker [Plate I, Fig. 1].

Head black or very dark brown; with the mandibles (except a narrow margin), the clypeus (except a large arrow-shaped mark in the middle), a somewhat triangular spot on front, the sinus and the space above and behind the eye yellow [in some cases the yellow has a brownish tinge]. Antennae black, with the scape yellow in front and the flagellum sometimes slightly brownish beneath. Thorax dark-brown to black; with the posterior border of the prothorax, a more or less narrow line in front, two longitudinal stripes on the mesothorax, the borders of the tegulae, the scutellum (except a median line) a transverse line on the post-scutellum, two large irregular spots on the metathorax, a broad band on the mesopleura, two spots on the metapleura yellow. Abdomen black or a very dark brown, with a narrow transverse band on the posterior border of each segment, a narrow transverse band on the anterior border of the first segment, and a narrow transverse band across the second segment, a transverse band across the posterior margin of the ventral side of each segment and large blotches on the ventral side of the second segment yellow. The transverse band across the middle of the dorsal surface of the second segment is slightly ferruginous and is interrupted in the middle; legs yellow, more or less tinged with ferruginous, anterior border of femur brown to black, wings smoky with nervures brown.

The length of the workers of this nest ranged from thirteen to fifteen millimeters. The length of the head was $2 \mathrm{~mm}$., the width from $4 \mathrm{~mm}$. to $5 \mathrm{~mm}$., the height from $3.5 \mathrm{~mm}$. to $4 \mathrm{~mm}$. The length of the thorax was from $4 \mathrm{~mm}$. to $5 \mathrm{~mm}$, , the width $4 \mathrm{~mm}$., the height $4 \mathrm{~mm}$. The length of the abdomen was $7 \mathrm{~mm}$. to $9 \mathrm{~mm}$., the width from $4 \mathrm{~mm}$. to $5 \mathrm{~mm}$., the height $3.5 \mathrm{~mm}$. to $4 \mathrm{~mm}$.

\section{Description of the Male [Fig. 6].}

The coloration of the head is similar to that of the worker, but the dark blotch is absent from the clypeus. The coloration of the thorax is similar to that of the worker, but the yellow is absent from the metathorax. From the dorsal aspect the coloration of the abdomen is similar to that of the worker. The coloration of the ventral side of the abdomen is similar to that of the worker but the ground plan is more reddish and the yellow markings less distinct. Indeed throughout the yellow is more indistinct on the male than on the female. 


\section{Explanation of Figures, Plate I.}

Fig. 1-Worker Vespa carolina Dr.

Fig. 2-Head of the worker Vespa carolina (front view).

Fig. 3 - Front wing of Vespa carolina.

Fig. 4- Head of the female Vespa carolina (front view).

Fig. 5-Female Vespa carolina.

Fig. 6-Male Vespa carolina.

Fig. 7-Hind wing of Vespa carolina.

Haines Normal School,

Augusta, Ga., Nov. 1st, 1907.

\section{RECENT ENTOMOLOGICAL LITERA'TURE.}

Mosquito Life.- By Evelyn Groesbeeck Mitchell. G. P. Putnam's Sons, New York and London. The Knickerbocker Press, 1907, 281 pp. illus., plates.

This is an interesting book upon a very important subject. When we consider that the mosquito is one of the great carriers of diseases, we should inform ourselves on this subject for self protection. Since the discovery that the mosquito is a transmitter of diseases, volumes, we might say, have been written, but many of these valuable papers are either scattered and inaccessible, or too technical for the average reader. The authoress has succeeded in presenting a very clear and condensed account of our present knowledge of this great subject. The work is well arranged, with good typography and numerous excellent illustrations. The volume embraces chapters on: Systematic position and structure; Habits; How far mosquitoes fly; The larvae and pupae; The transmission of malaria, yellow fever and other diseases; Remedies and enemies; Notes on the commoner species. Collecting and laboratory methods, and keys to identify not only the adults, but also the eggs, larvæ and pupæ, followed by a systematic list of the genera and species. The book closes with an appendix - Mosquito and Leprosy - in which some theories bearing on the transmission of this disease are discussed. The work is dedicated to the memory of Dr. James William Dupree. 
PSYCHE, VOL. XV.

PLATE I.

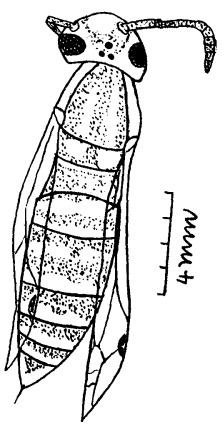

\section{Fig. I}

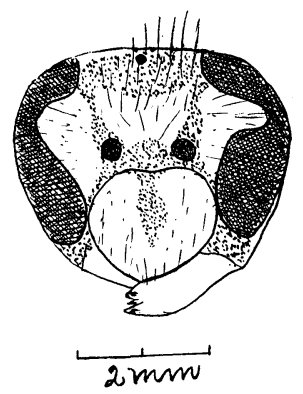

Fig. 2

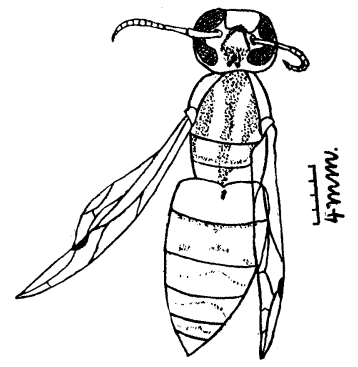

Fig.5

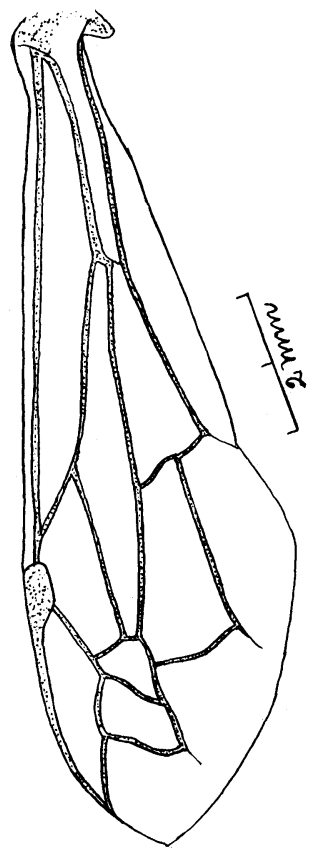

Fig. 3

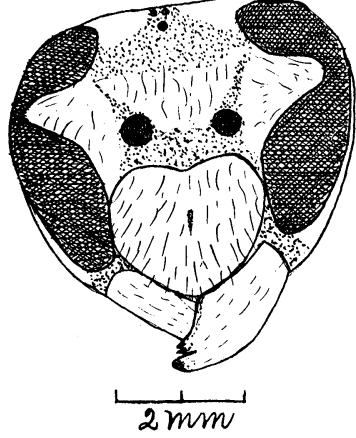

Fig. 4

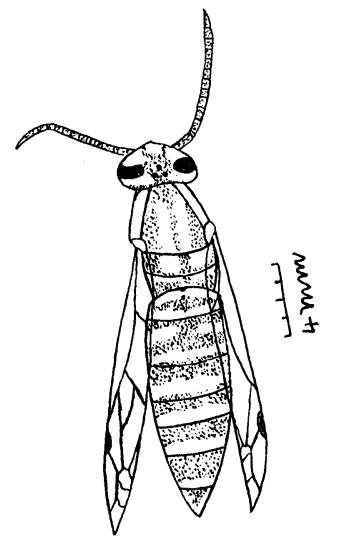

Fig. 6

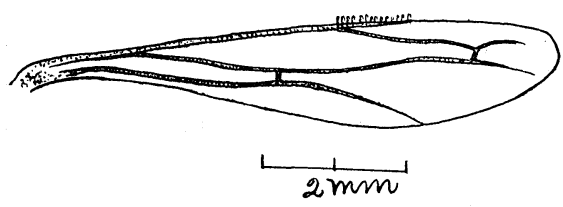

Fig. 7

TURner : Vespa Carolina. 

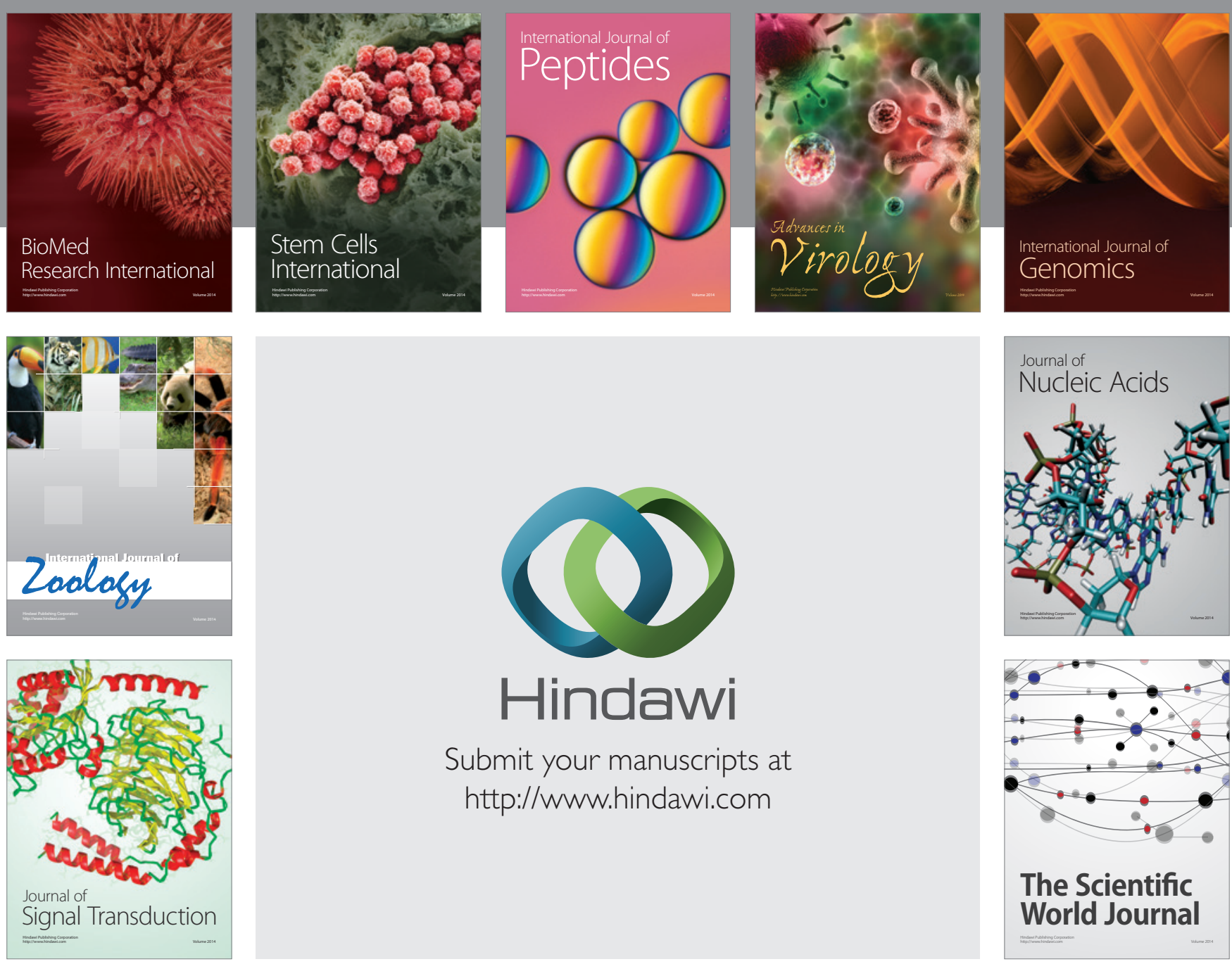

Submit your manuscripts at

http://www.hindawi.com
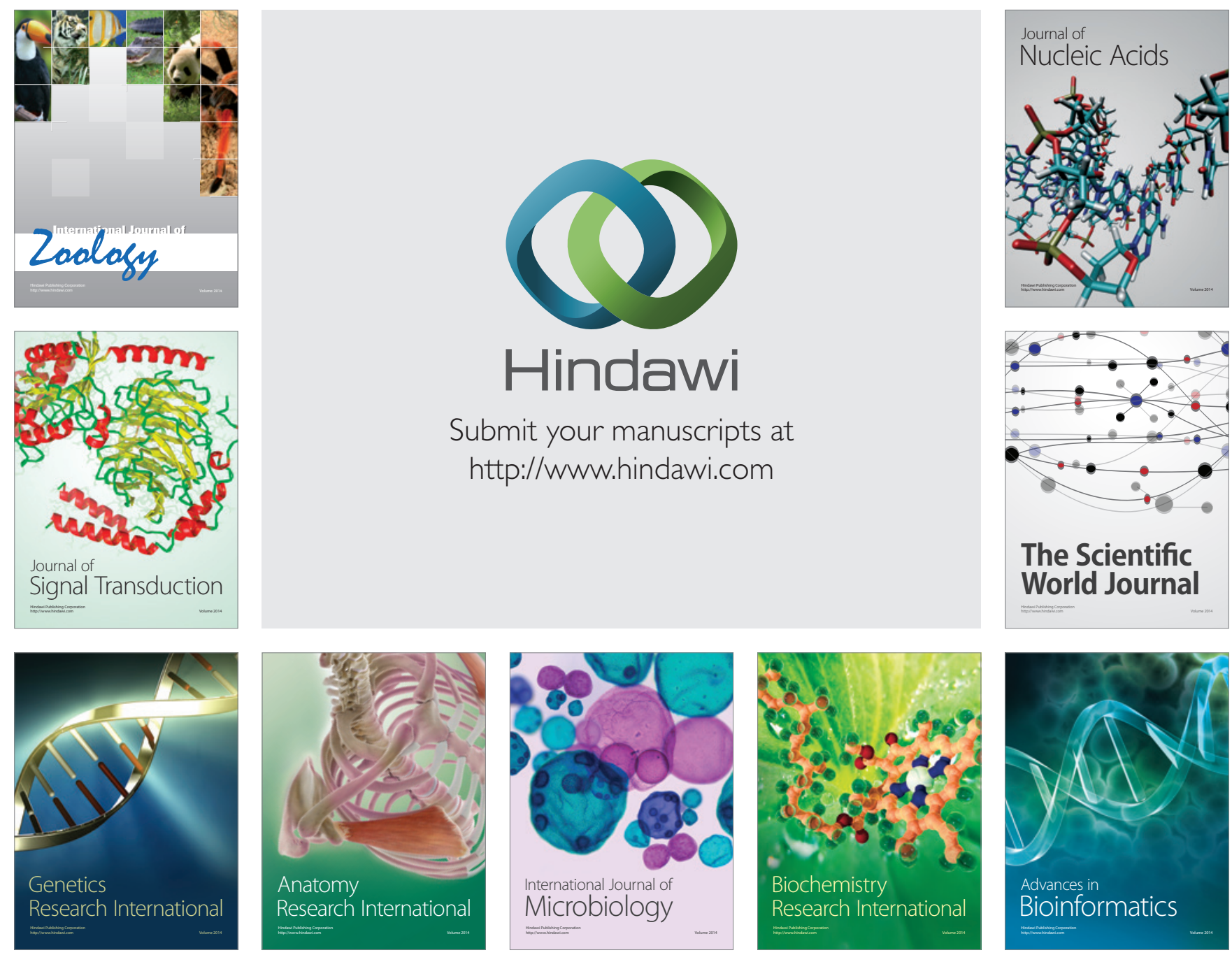

The Scientific World Journal
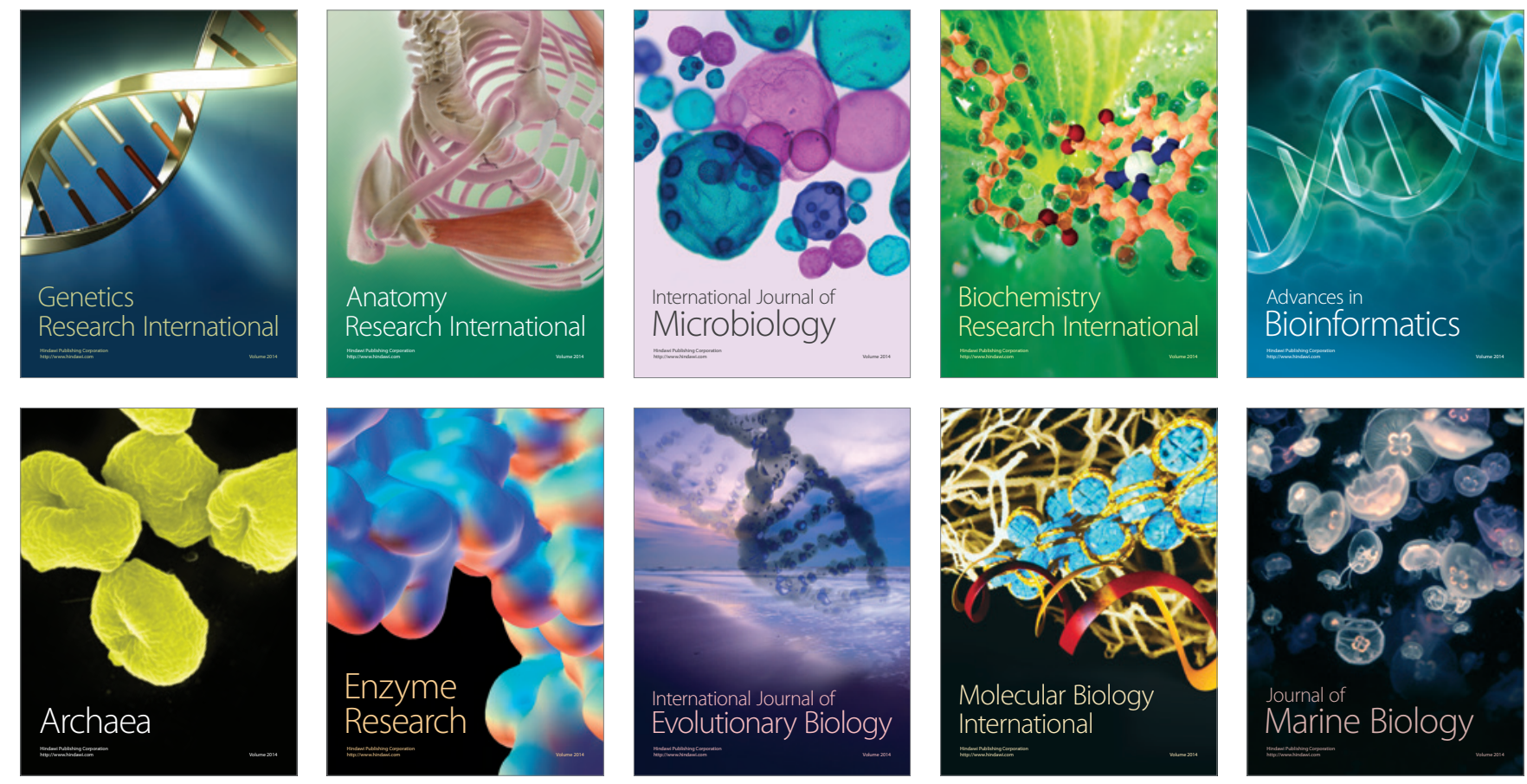